\title{
Discontinuous Precipitation and Dissolution under the Influence of the Plastic Strain and Temperature in Al-15 at. $\%$ Zn and Al-30 at. $\%$ Zn Alloys
}

\author{
Mazouz Hamoudi, Bensaada Said, Mohamed Tewfik, Bouziane, Laboratoire Larhyss
}

Université de Biskra, Biskra, Algerie.

Email: Bensaada52@yahoo.fr

Received March 15 ${ }^{\text {th }}, 2012$; revised April 21 $1^{\text {st }}, 2012$; accepted May $25^{\text {th }}, 2012$

\begin{abstract}
The discontinuous precipitation and dissolution in the alloy Al-Zn system has been the subject of many theoretical and experimental investigations that have contributed to the understanding of the different mechanisms which control them. However, many questions remain unanswered because of the complexity of the constituted phases which are affected by the speed of the quenched, deformation, the temperature of homogenization and ageing effect. The purpose of this work is to clarify the effect of temperature and deformation on the mechanisms of these two reactions during ageing of Al-15 at.\% $\mathrm{Zn}$ and $\mathrm{Al}-30$ at.\% $\mathrm{Zn}$ alloy. The techniques of analysis used in this respect are the optical microscopy, the X-ray diffraction and the hardness Vickers.
\end{abstract}

Keywords: Alloy Al-Zn; Discontinuous Precipitation; Dissolution; Temperature; Deformation

\section{Introduction}

\subsection{Discontinuous Precipitation}

The first appearance of the DP was in 1930 [1]. Since then, more than 700 publications on DP have been reported in the literature. However, it is surprising that the precise conditions in which it occurs or is preferred to continuous precipitation (CP) have not yet been clearly identified [2]. Discontinuous precipitation involves the decomposition of a supersaturated solid solution into two phases $\boldsymbol{\alpha}_{0}$ lamellar structure downstream of a moving grain boundary, one $\boldsymbol{\alpha}$-depleted alloy element and having the same structure as the phase and $\boldsymbol{\alpha}_{0}$ the other rich in $\boldsymbol{\beta}$ phase precipitated alloying element, it is symbolized by the following equation:

$\boldsymbol{\alpha}_{\boldsymbol{0}} \rightarrow \boldsymbol{\alpha}+\boldsymbol{\beta}$ and Figure 1 [3]. This reaction is governed by the grain boundary diffusion at wide angle, which is always effective to allow formation cellular.

The interest which attaches to the study of discontinueous precipitation in alloys of the $\mathrm{Al}-\mathrm{Zn}$ comes from the fact that it has a detrimental effect on mechanical properties, physical and chemical properties of many engineering alloys. Unlike the continuous precipitation or the matrix is depleted in solute continuously over time, in the case of discontinuous precipitation, both the existence of a discontinuous change of direction and a sudden change concentration of solute on either side of the front migration reaction [4].

In a study by S. Abdou [5] on alloys of this system, it was found that the nucleation occurs not only at grain boundaries at all angles, but also in structural defects. Generally, studies on discontinuous precipitation in this alloy system are made in isothermal conditions in preference to high supersaturations and low temperatures $\left(62^{\circ} \mathrm{C}\right.$ to $\left.150^{\circ} \mathrm{C}\right)$, although the grain boundary mobility is low in alloys of this system [6].

The plastic deformation introduced additional structural defects in the matrix such as dislocations, which increase the favourable sites for cellular precipitation, because the dislocations are aligned to form additional grain boundaries, which promotes this type of decomposition $[7,8]$. However, in some alloys, the restrain delays or completely eliminates the discontinuous precipitation $[9,10]$. The previous work does not cover a wide range of

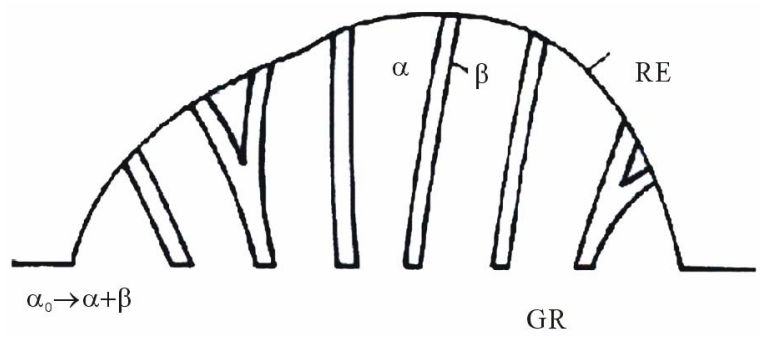

Figure 1. Schematic of discontinuous precipitation [3]. 
strain rates and found in the study of the effect of cold plastic deformation during ageing at $470{ }^{\circ} \mathrm{C} 2 \mathrm{mass} \% \mathrm{Cu}-$ $\mathrm{Be}$, that a deformation rate of $0 \%-20 \%$ discontinueous precipitation retards by cons rate of $20 \%-50 \%$ accelerates and $50 \%-70 \%$ slow it down and over $70 \%$ of total abolition. However, a localized deformation such as a fingerprint or a scratch hardness of the surface can initiate discontinuous precipitation in these areas [11-14].

Discontinuous precipitation in alloys of Al-Zn system is characterized by complex metastable phases formed and they are is sensitive to quench rate, the homogenization temperature and amount of impurity [5]. These types of alloys does not remain homogeneous after quenching, because the matrix contains $\boldsymbol{\alpha}_{0}$ concentration fluctuations, which are known by the Guinier-Preston zones (GP) or stage of pre-precipitation could affect the growth of cellular precipitates.

However, before the formation of the equilibrium phase $\boldsymbol{\beta}$-rich element $\mathrm{Zn}$, appear first metastable phases named GP form of segregation or clusters that retain the structure of the solid solution $\boldsymbol{\alpha}_{0}$ and are fully consistent and second phase appears in R. The sequence of formation of precipitate in the solid solutions of Al-Zn system is as follows $[5,15,16]$.

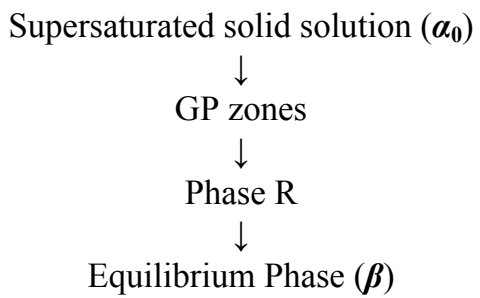

The process of formation of metastable phases is dc $[17,18]$, affecting the kinetics of discontinuous precipitation, either by reducing the driving force and/or by provoking a physical obstruction to the movement of reaction front [19]. This phenomenon has been observed in alloys of the Al-Zn [20,21]. In the alloy Ti-Fe-Co this is due mainly to the reaction of spinodal decomposition $[22,23]$.

The formation of metastable phases is accompanied by an increase in elastic strain due to the coherence and distortions resulting network and when they reach the value of the shear strength of the matrix, the consistency is broken and dislocations of accommodation form, which gives the lowering of hardness. In reality these metastable phases of transition that may occur are difficult to distinguish from the stable phase by metallography.

However, the mechanism of Tu and Turnbull [24] is unlikely in this alloy system, an alternative mechanism suggested by Fournelle and Clark [25] is the most plausible. According to Peterman et al. [26], the cells appear only on one side of the grain boundary, then one seam is developed, however, the grain boundary deforms and moves in two opposite directions from its initial position, which gives a double seam (S mechanism). Bauman et al. [27] showed that low temperatures generally lead to the ageing mechanism $\mathrm{S}$, against high ageing temperatures promote the unique morphology of the seam.

\subsection{Dissolution of Cellular Precipitate}

The reverse process of discontinuous precipitation is the dissolution of the precipitate in the matrix cell $\boldsymbol{\alpha}_{0}$, or the reaction front formed during the discontinuous precipitation migrates in opposite directions in the two-phase structure $[28,29]$ and according to the reaction

$$
\boldsymbol{\alpha}+\boldsymbol{\beta} \rightarrow \boldsymbol{\alpha}^{\prime}
$$

Studies done by Pawlowski and Truszkowski [30] showed that the reaction of dissolution of precipitates in the cellular system Al-Zn alloy is controlled by volume diffusion process and can be done in two modes continuous and discontinuous. M. Sulonen [31] showed that the prestrain leads to faster dissolution of the latter to continued dominance by the dissolution reaction cons is an intermittently in samples not deformed. The dissolved phase leads to hardening of the alloy, it increases the voltage due to the precipitate rich in solute, by introducing it into the matrix [30]. Cons by continuous dissolution can have a positive effect on the mechanical properties of alloys in general, because it can cause the grain refining [31]. It was established that only a long homogenization annealing of several hours may lead to a complete dissolution of the particles of the second phase $\boldsymbol{\beta}$ formed during the discontinuous precipitation.

\section{Experimental Methods}

The alloys in question were prepared by melting under inert atmosphere (Argon) from aluminum (3NAL) and Zinc (Zn 4N5) very pure. The ingots obtained were subjected to a first homogenization annealing for 2 days at $\mathrm{T}$ $=350^{\circ} \mathrm{C}$, followed by a second homogenization annealing for 21 days at $\mathrm{T}=400^{\circ} \mathrm{C}$ and quenched in a methanol-salt solution Ice- $\mathrm{T}=-10^{\circ} \mathrm{C}$. For the demonstration of the effect of temperature we chose two aging temperatures of $75^{\circ} \mathrm{C}$ and $160^{\circ} \mathrm{C}$ and the effect of cold plastic deformation several samples at different strain rates were used. So that samples do not undergo oxidation during annealing processes, a set of vacuum annealing was designed. The used reagent is a solution consisting of $15 \mathrm{ml}$ of hydrofluoric acid, nitric acid $15 \mathrm{ml}$ and $30 \mathrm{ml}$ of glycerin with the attack time is 10 to 30 seconds. The analytical techniques used in this regard are: optical microscopy, X-ray diffraction and Vickers hardness (HV). 


\section{Results and Discussion}

\subsection{Ageing at $75^{\circ} \mathrm{C}$}

The structural evolution during ageing at $75^{\circ} \mathrm{C}$ and a holding time of 22 hours of the alloy Al-15 at.\% $\mathrm{Zn}$ for the samples showed that the deformation rate is between $45 \%$ and $55 \%$ discontinuous precipitation located mainly along the grain boundary (Figure 2(a)), by cons in the samples to strain rates below $45 \%$ and above $55 \%$ or it develops very slowly and in interaction with recrystallization, or it is totally absent (Figures 2(b) and (c)). However it is certain that if recrystallization occurs at lower ageing temperature, it substantially eliminates defects promote the precipitation and the effect of the deformation is more pronounced at this temperature.

The appearance of precipitate in the samples at strain rates between $45 \%$ and $55 \%$ is probably a weak interacttion between the discontinuous precipitation and recrystallization. So the plastic deformation does not support the discontinuous precipitation especially at low temperature in the alloy Al-15 at.\% Zn. It is not a major factor contributing to the stimulation of the precipitate in this type of alloy. The best contribution to hardening structural proved to be one of the intermediate phase, given the size of its particles and their degree of dispersion in the matrix, the alloy softens and its properties fall more with the precipitate of equilibrium (Figure 3 ).

Figure 4 shows the early development of the mechanism S (double seam), which is the most dominant in this type of alloy and at this temperature. Similarly the spectra of X-ray diffraction confirm the emergence of a second phase during annealing at $75^{\circ} \mathrm{C}$ (Figure 5).

\subsection{Ageing at $160^{\circ} \mathrm{C}$}

\subsubsection{Case of the Alloy Al-15 at.\% Zn}

Unlike the ageing temperature at $75^{\circ} \mathrm{C}$, the high density of dislocations introduced by plastic deformation in the alloy in question, and the aging temperature of $160^{\circ} \mathrm{C}$ could stimulate the process of diffusion and growth of the precipitate in lamellar all samples regardless of strain rate (Figures 6(a)-(c)). However the effect of temperature and strain rate is very clear, because the germination process is much faster for high strain rates.

Therefore the temperature of $160^{\circ} \mathrm{C}$ favored only the discontinuous precipitation, growing by diffusion from the grain boundaries. Prolonging the annealing time up to 172 hours has led to growth arrest of the precipitate and this is probably the spinodal decomposition, because at this stage no recrystallization was observed, as Figure 7 shows the softening of the alloy, thus confirming the occurrence of precipitated phase equilibrium.

\subsubsection{Case of the Alloy Al-30 at.\% Zn}

For the alloy Al-30 at.\% Zn was chosen two types of samples, first underwent a cold plastic deformation prior to homogenization treatment at $400^{\circ} \mathrm{C}$ and the second is deformed after the homogenization treatment also at $400^{\circ} \mathrm{C}$.

\subsubsection{First Case: Deformations before Homogenization}

Figure 8 shows the microstructures after ageing at $160^{\circ} \mathrm{C}$ deformed samples before homogenization and ageing at $160^{\circ} \mathrm{C}$. We note that:

1) The discontinuous precipitation develops in all samples and the effect of strain rate is clear, since the amount of precipitate increases with increasing plastic strain rate (Figure 8).

2) Cellular precipitation inside the grain is possible, and the amount of precipitate also increases with increasing dislocation sites (Figure 8(c)). It is due to a formation of sub-grains after thermomechanical treatment, i.e., plastic deformation and after annealing at $400^{\circ} \mathrm{C}$.

3) We can see that competition between the reaction of recrystallization and precipitation from a rate of $35 \%$ plastic deformation (Figure 8(b)). On the other hand, in this case, the evolution of the hardness is represented by Figure 9. One can observe that most of the curves $(1,2$,
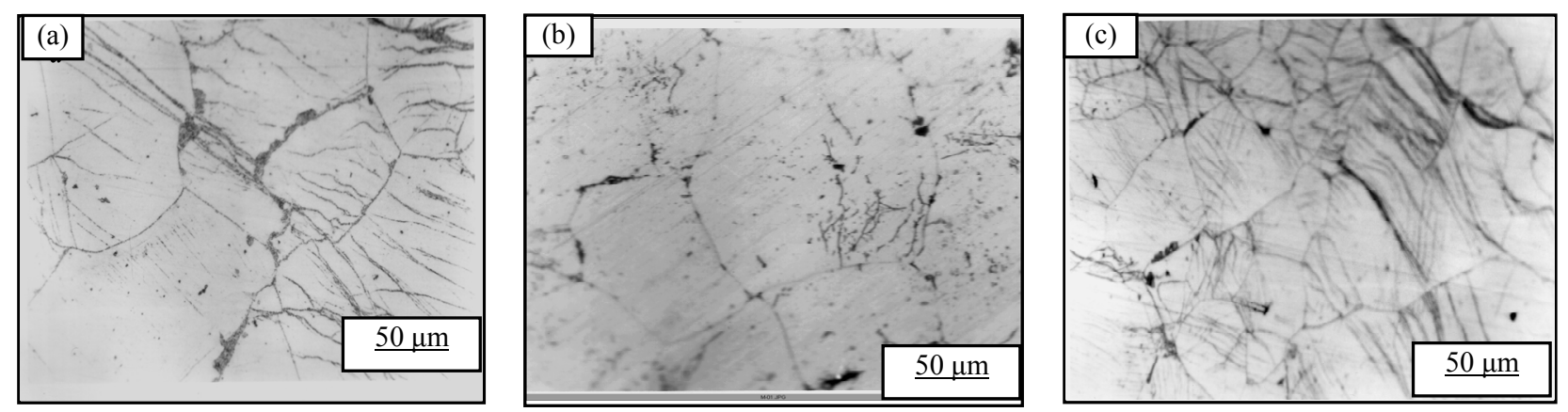

Figure 2. Structural evolution of the alloy $\mathrm{Al}-15$ at. Homogenised for $21 \% \mathrm{Zn}$ days at $400^{\circ} \mathrm{C}$, dipped in methanol-salt-ice at $-10^{\circ} \mathrm{C}$, deformed $55 \%$ (a) $20 \%$ (b) and $72 \%$ (c), then aged at $75^{\circ} \mathrm{C}$ for 22 hours. 


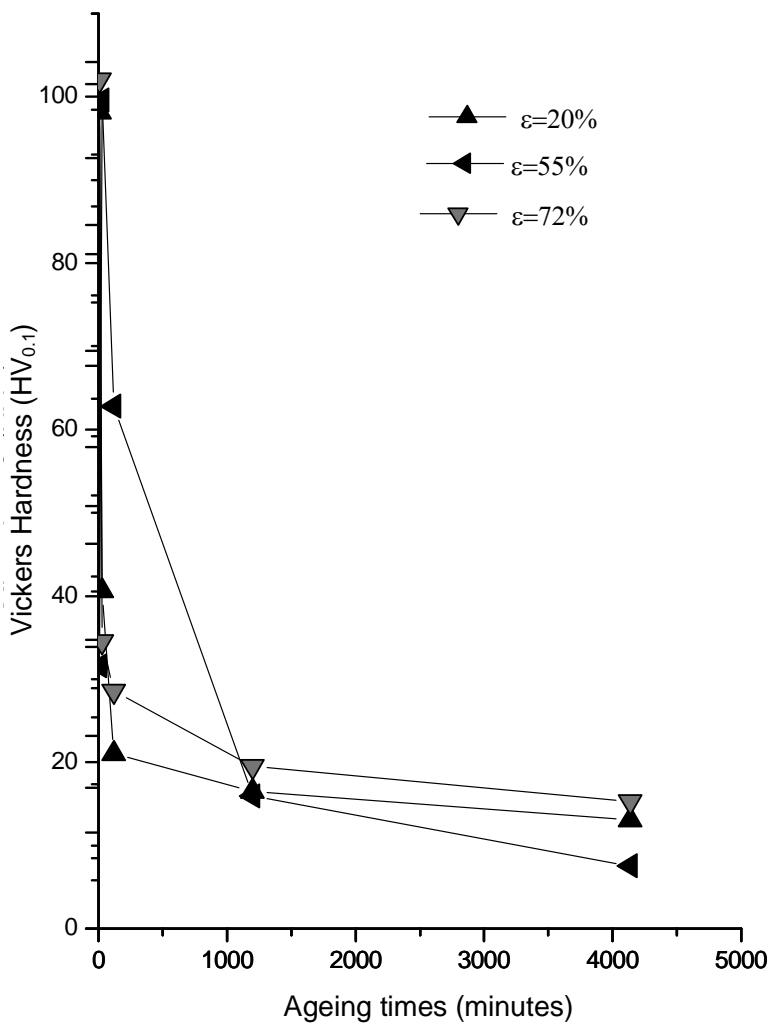

Figure 3. Evolution of microhardness HV of the alloy Al-15 at. \% $\mathrm{Zn}$ homogenized for 21 days at $400^{\circ} \mathrm{C}$, dipped in methanol-salt-ice at $-10{ }^{\circ} \mathrm{C}$, deformed by $55 \%, 20 \%$ and $72 \%$, then aged at $75^{\circ} \mathrm{C}$ for 22 hours.

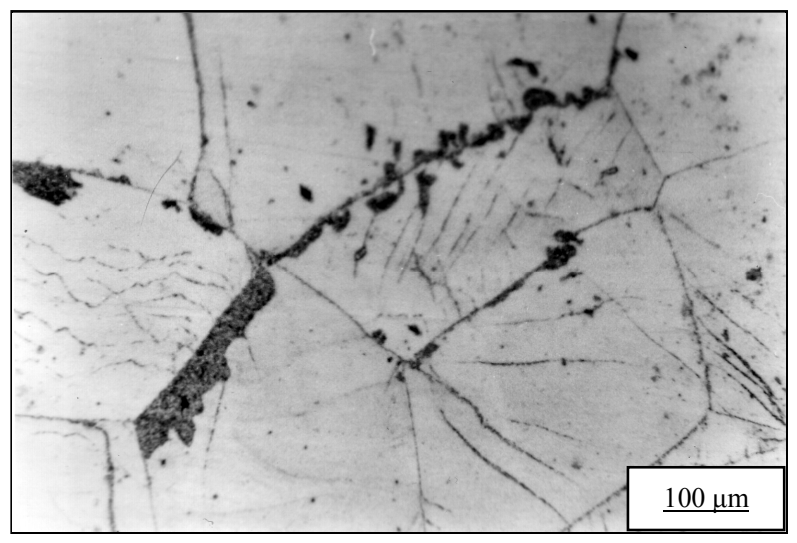

Figure 4. Demonstration of mechanism $\mathrm{S}$ in the alloy Al-15 at.\% Zn homogenized for 21 days at $400 \mathrm{C}$, dipped in methanol-salt-ice $-10^{\circ} \mathrm{C}$, deformed $55 \%$, then aged at $75^{\circ} \mathrm{C}$ for 22 hours.

3, 4 and 5) are characterized by a maximum hardness during the first phase of ageing; it is probably due to precipitation of GP zones generally. The hardness begins to decrease slowly after extending the ageing time.

\subsubsection{Second Case: Deformations after Homogenization}

In this part of the samples are deformed after homogenization at $400^{\circ} \mathrm{C}$, then ageing at $160^{\circ} \mathrm{C}$. Figure 10 reveals the following remarks:

1) The discontinuous precipitation occurs only for low

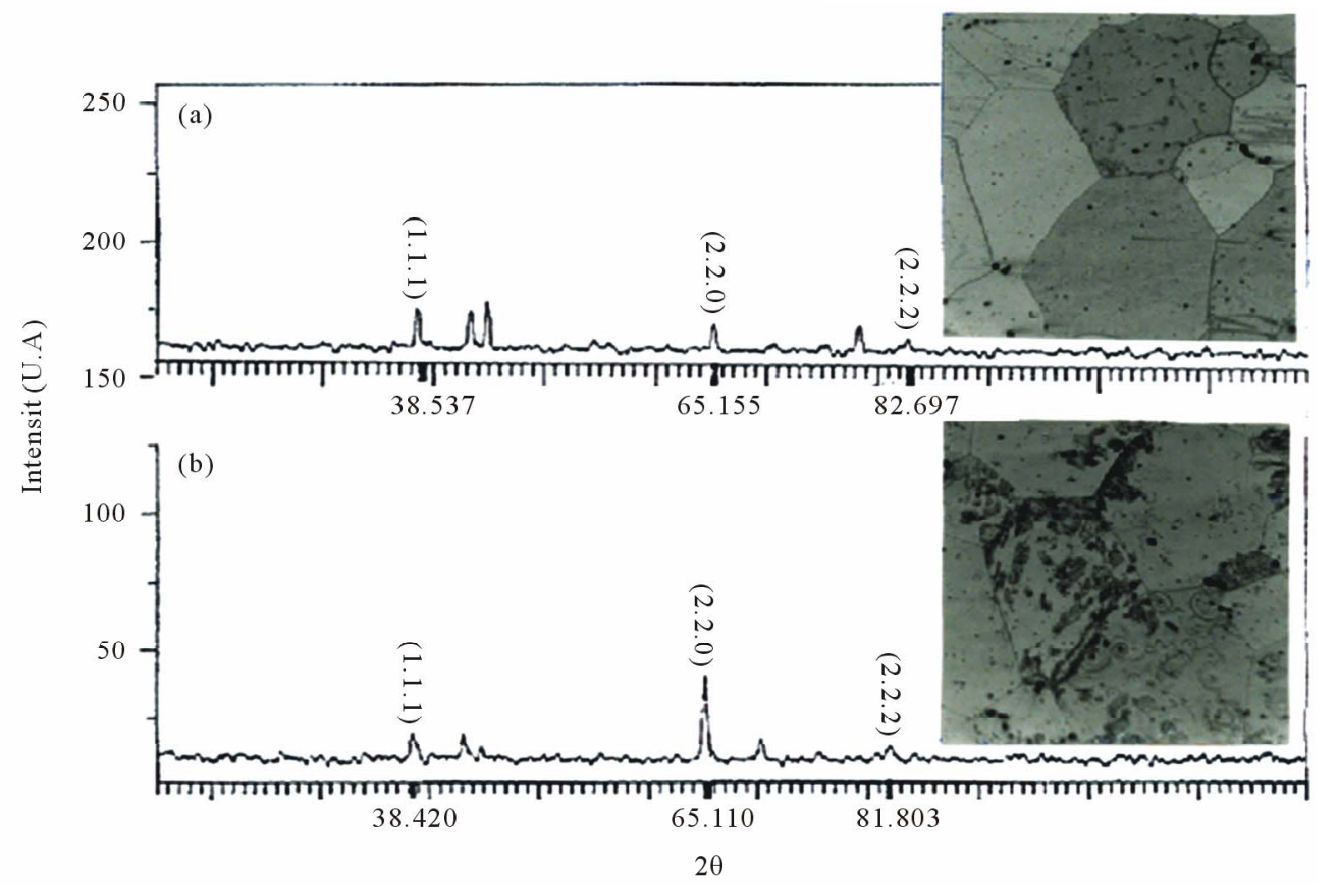

Figure 5. Spectra of X-ray diffraction of the alloy Al-15 at.\% $\mathrm{Zn}$ homogenized for 21 days at $400^{\circ} \mathrm{C}$, dipped in methanolsalt-ice $-10^{\circ} \mathrm{C}$, deformed $55 \%$ (a), then aged at $75^{\circ} \mathrm{C}$ for 22 hours (b). 


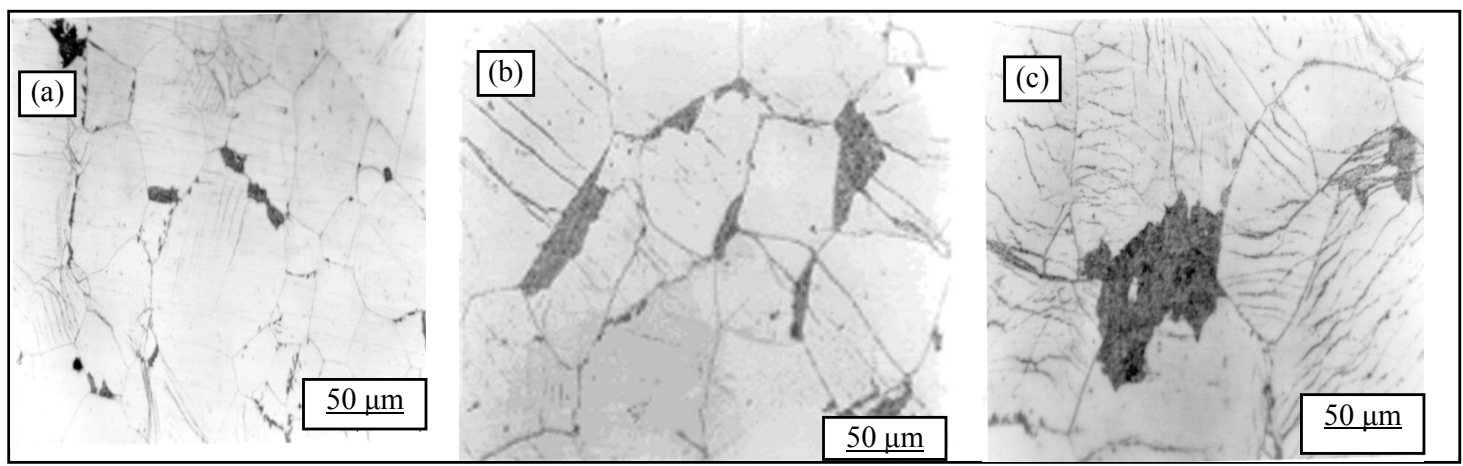

Figure 6. Structural evolution of the alloy Al-15 at. Homogenised for $21 \% \mathrm{Zn}$ days at $400^{\circ} \mathrm{C}$, dipped in methanol-salt-ice at $-10^{\circ} \mathrm{C}$, deformed $55 \%$ (a) $20 \%$ (b) and $72 \%$ (c), then aged at $160^{\circ} \mathrm{C}$ for 22 hours.

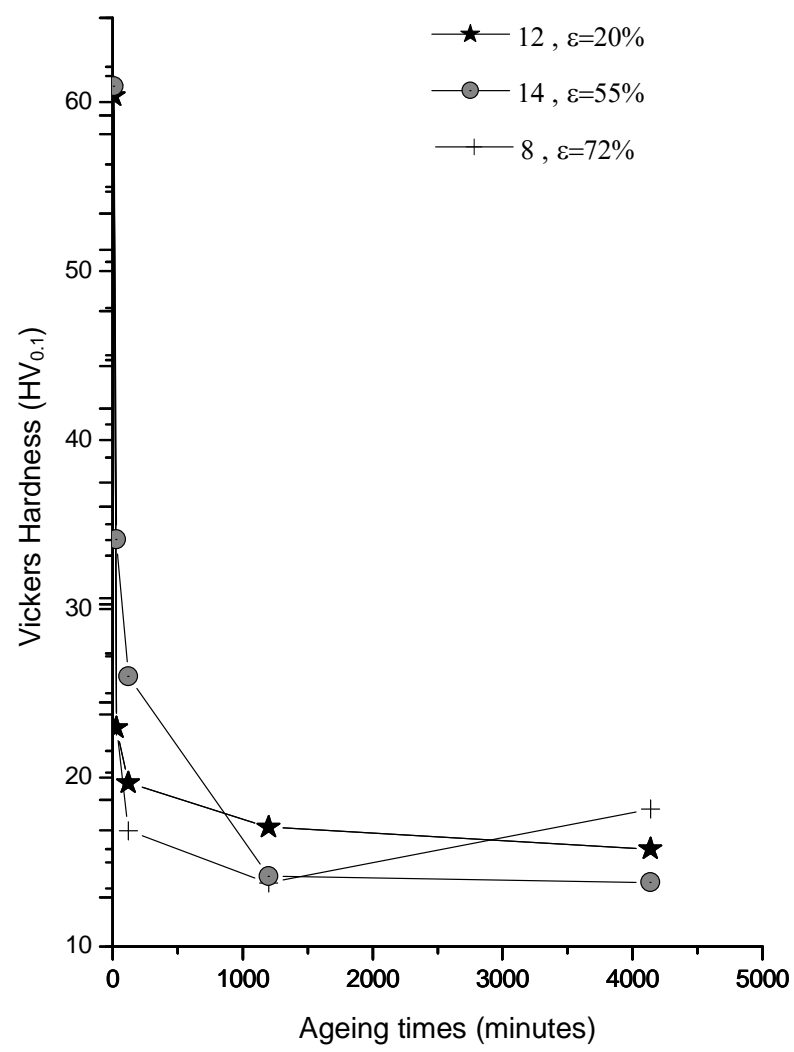

Figure 7. Evolution of the hardness HV of the alloy Al-15 at. $\% \mathrm{Zn}$ homogenized for 21 days at $400^{\circ} \mathrm{C}$, dipped in methanol-salt-ice at $-10{ }^{\circ} \mathrm{C}$. Deformed by $55 \%, 20 \%$ and $72 \%$, then aged at $160^{\circ} \mathrm{C}$ for 22 hours.

plastic strain rate (Figure 10(a))

2) For high strain rate plastic, There are no discontinuous precipitation and the structure is characterized by slip bands (Figure 10(c)) and this structure remains unchanged even after extended ageing (Figure 10(d)).

3) The mechanism of recrystallization is observed for low degree of plastic deformation of $23 \%$ to $51 \%$ and this reaction occurs after the discontinuous precipitation (Figure 10(b)).
The same evolution of the hardness is observed in this second type of samples (Figure 11). The X-ray diffraction revealed the presence of two phases (the $\boldsymbol{\beta}$ precipitate and the equilibrium phase $\alpha$ ) (Figure 12).

\subsection{Dissolution of Lamellar Precipitate}

The annealing temperature of $295^{\circ} \mathrm{C}$ took a dissolution controlled by volume diffusion with immobility of grain boundary (Figure 13), so the continuous mode of dissolution is most likely in this type of alloy and at this temperature.

The dissolution is accompanied by a hardening of the alloy with no change in grain size (Figure 14). However, the optimal holding time can lead to complete dissolution can be estimated more accurately by X-ray diffraction.

\section{Conclusions}

The structural evolution during ageing of the alloy Al-15 at. $\% \mathrm{Zn}$ at $\mathrm{T}=75^{\circ} \mathrm{C}$ showed a discontinuous precipitation mainly located on grain boundaries and only in the samples to strain rates between $45 \%$ and $55 \%$, against the ageing of samples at strain rates below $45 \%$ and superior to $5 \%$ respectively led to a precipitation-recrystallization interaction and a lack of precipitation reaction. However, the mechanism $\mathrm{S}$ and the most dominant in this type of alloy. Unlike the $75^{\circ} \mathrm{C}$, ageing at $160^{\circ} \mathrm{C}$ could stimulate the discontinuous precipitation from the grain boundaries in all samples of alloys Al-15 at.\% $\mathrm{Zn}$ and Al-30 at.\% $\mathrm{Zn}$ whatever their rate of deformation, so the contribution of plastic deformation and temperature in the acceleration of the precipitation is very clear because it is much faster for high strain rates. However the extension of the duration of annealing leads to growth arrest of the precipitate and this is probably the spinodal decomposition.

For both ageing temperatures, the best contribution to the hardening of the alloy was found in the intermediate phase and with the appearance of equilibrium precipitate 


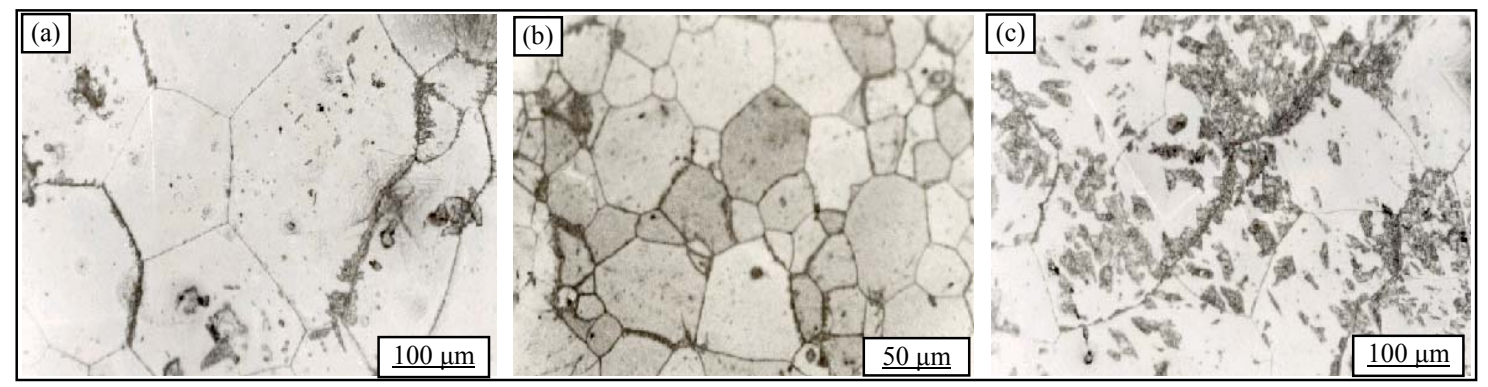

Figure 8. Structural evolution of the alloy $\mathrm{Al}-30$ at. $\% \mathrm{Zn}$ homogenized for 21 days at $400^{\circ} \mathrm{C}$, dipped in methanol-salt-ice at $-10^{\circ} \mathrm{C}$, deformed (a: $36 \%$, b: $48 \%$ and c: $76 \%$ ) before homogenization and then aged at $160^{\circ} \mathrm{C}$ for 22 hours.

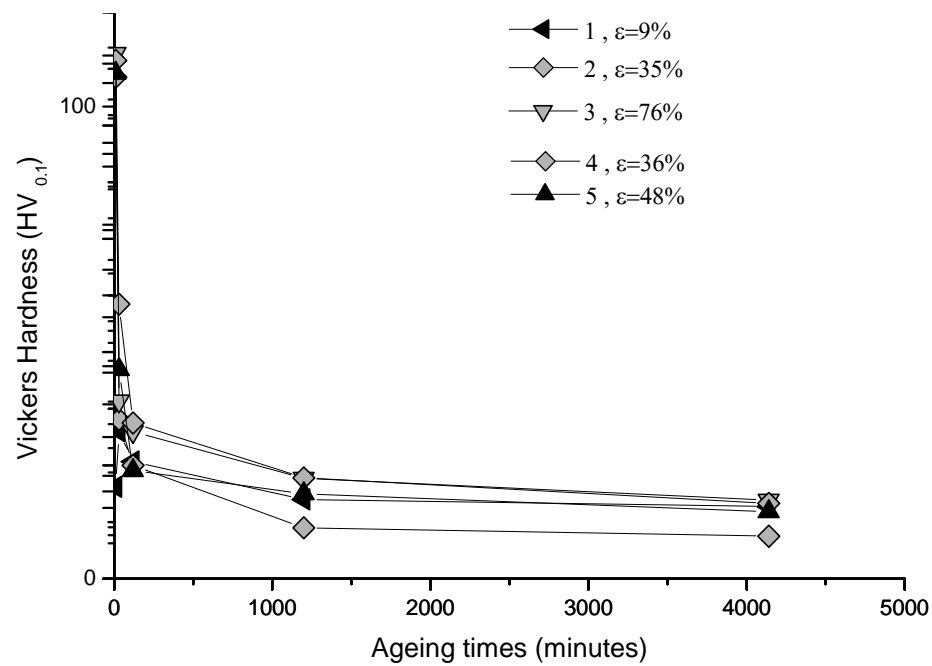

Figure 9. Evolution of the hardness $\mathrm{HV}$ of the alloy Al-30 at.\% $\mathrm{Zn}$, deformed then homogenized for 21 days at $400{ }^{\circ} \mathrm{C}$, dipped in methanol-salt-ice at $-10^{\circ} \mathrm{C}$, then aged at $160^{\circ} \mathrm{C}$.
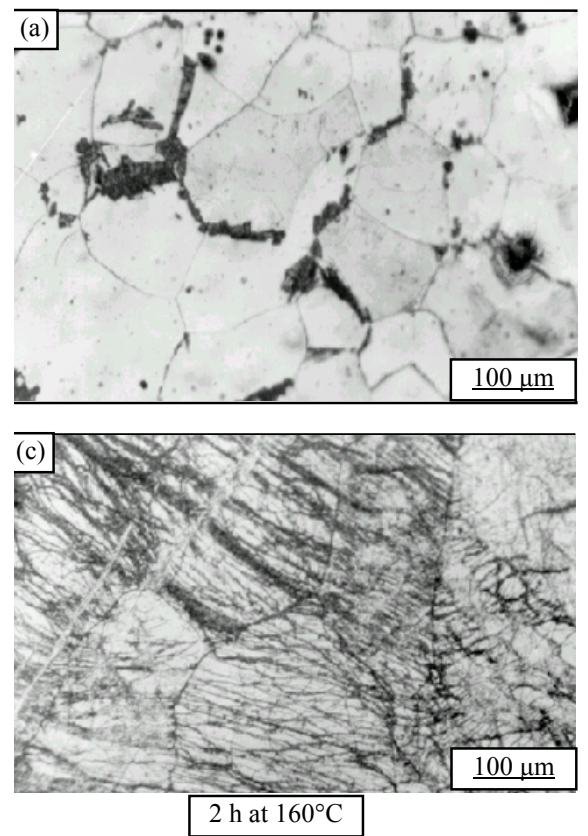
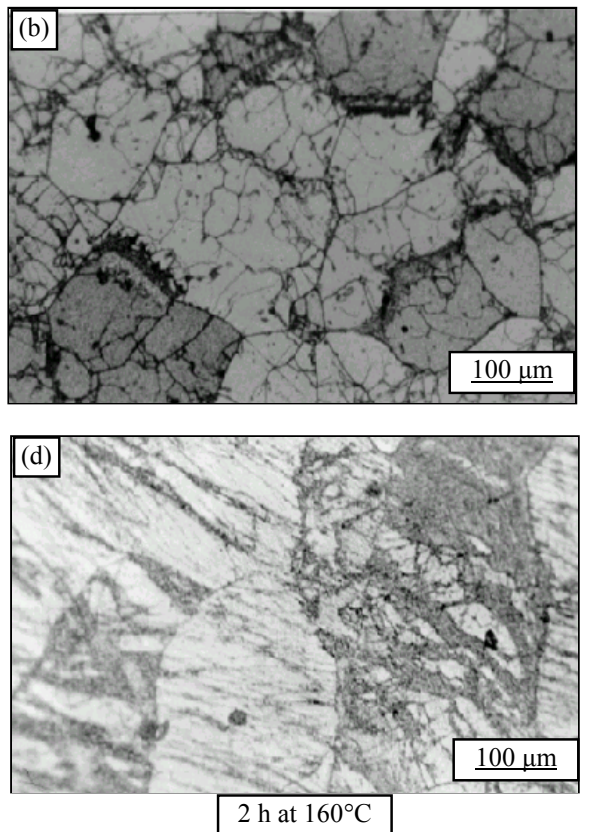

Figure 10. Structural evolution of the alloy Al-30 at.\% Zn, homogenized, deformed ((a), (b): 43\%; and (c), (d): 65\%) subsequently annealed at $160^{\circ} \mathrm{C}$. 

in Al-15 at.\% Zn and Al-30 at.\% Zn Alloys

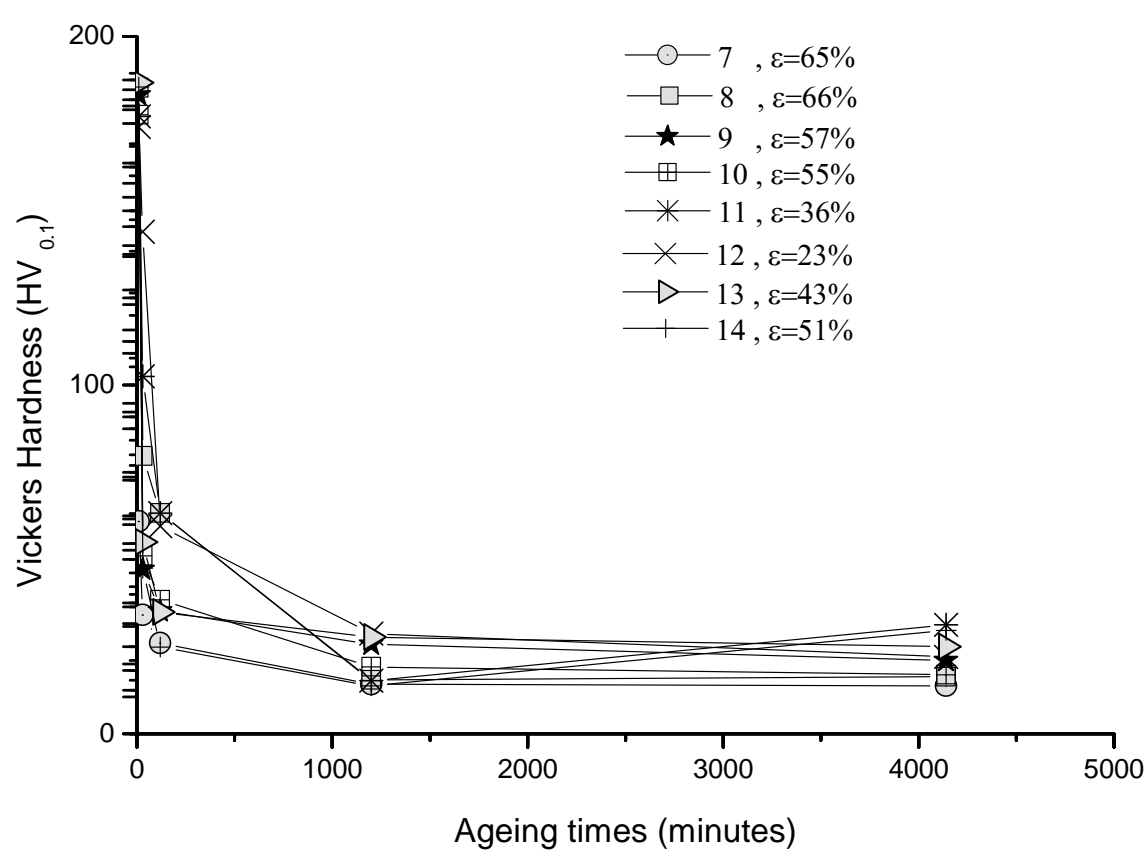

Figure 11. Evolution of the hardness $\mathrm{HV}$ of the alloy Al-30 at.\% $\mathrm{Zn}$, homogenized, deformed and then annealed at $160^{\circ} \mathrm{C}$.

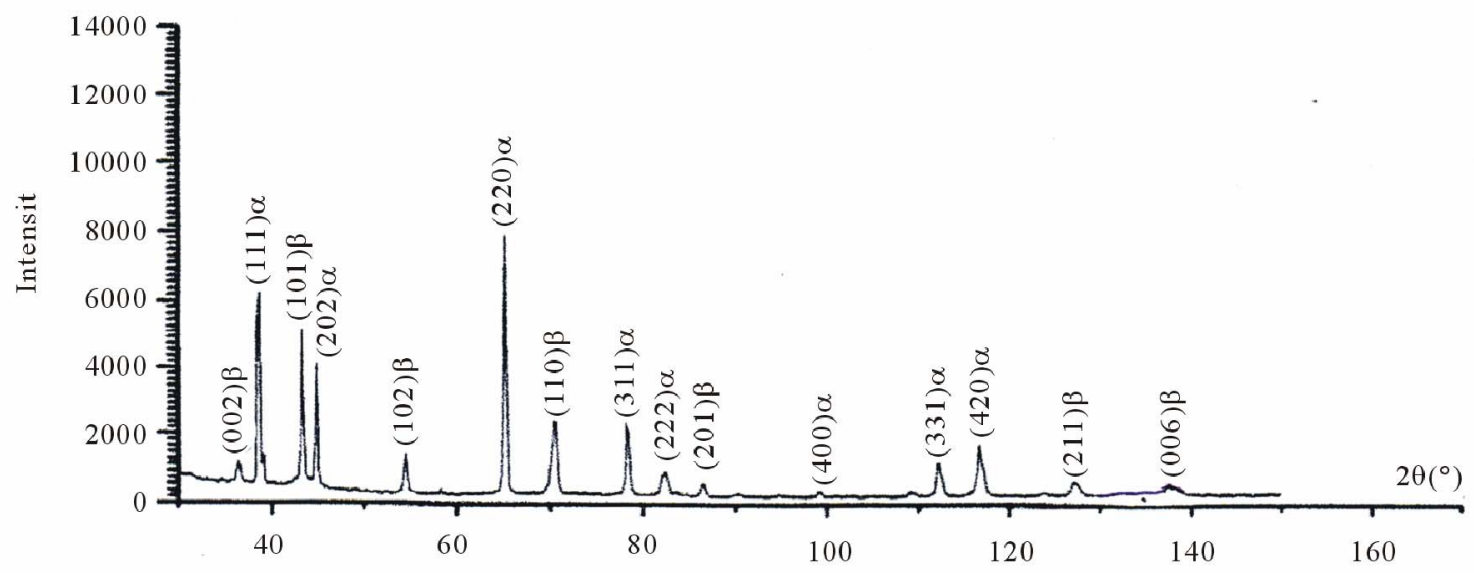

Figure 12. Spectra of X-ray diffraction of the alloy Al-30 at.\% $\mathrm{Zn}$ homogenized, deformed and then annealed at $160^{\circ} \mathrm{C}$ for 60 hours.

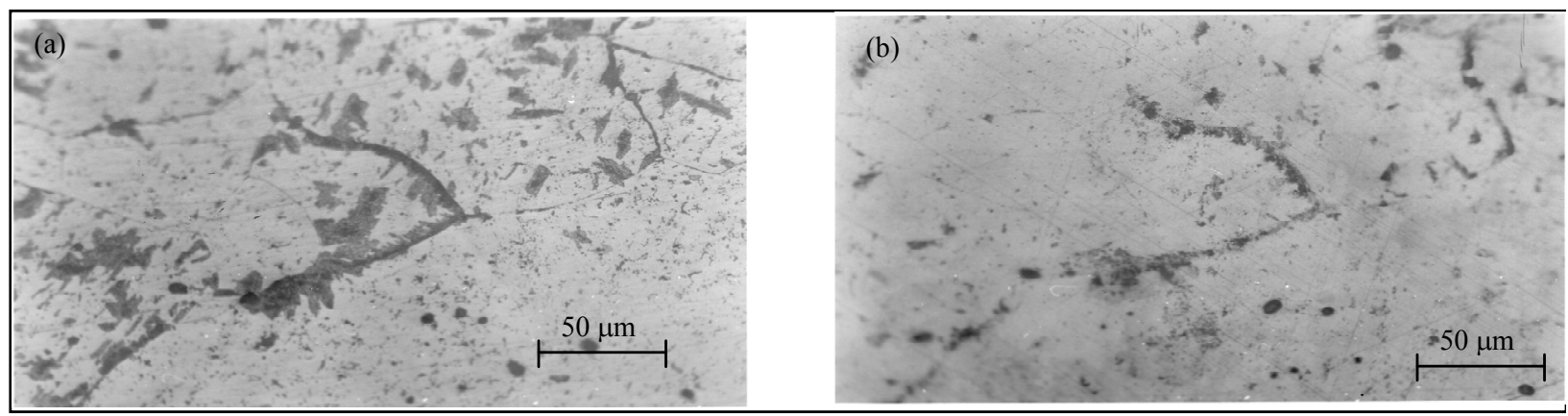

Figure 13. Structural evolution of the alloy Al-15 at.\% $\mathrm{Zn}$ homogenized for 2 days at $400^{\circ} \mathrm{C}$, dipped in methanol-salt-ice at $-10^{\circ} \mathrm{C}$, deformed $48 \%$, then aged at $160^{\circ} \mathrm{C}$ for 22 hours (a) and finally annealed at $295^{\circ} \mathrm{C}$ for 15 minutes (b). 


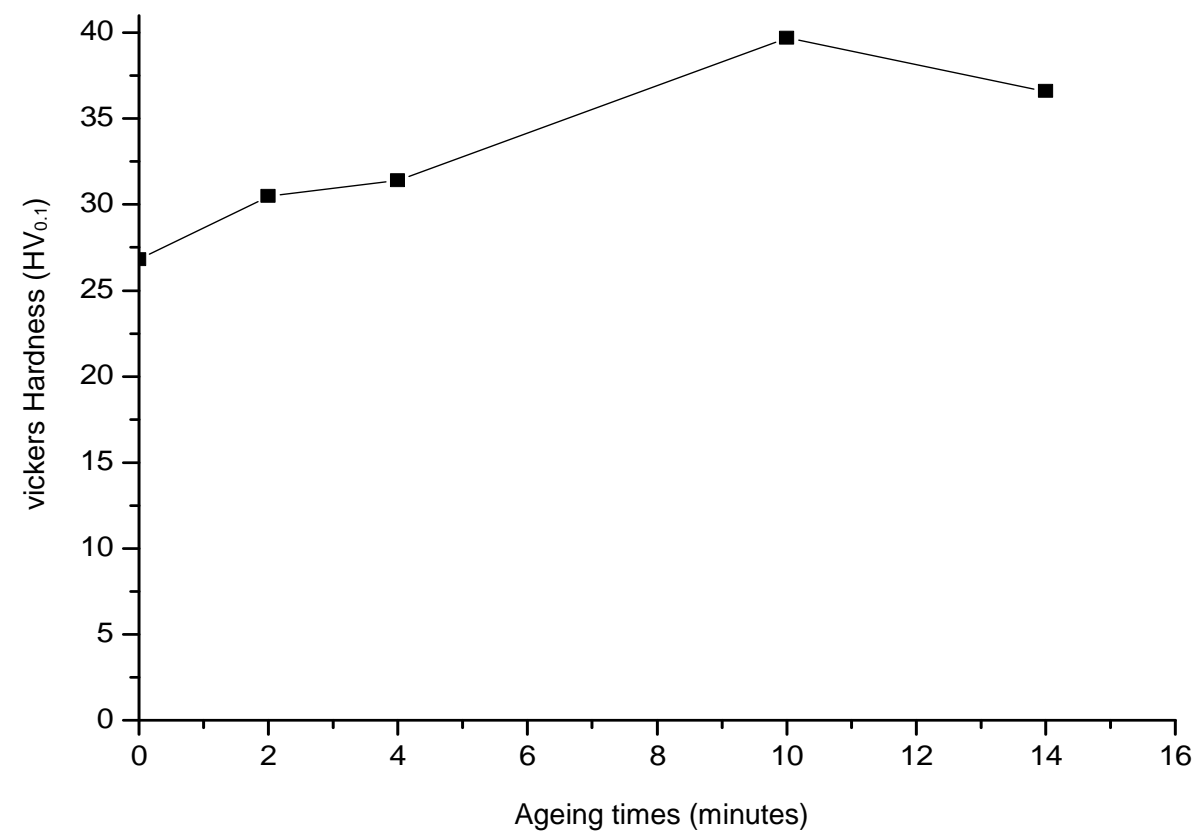

Figure 14. Evolution of microhardness $\mathrm{HV}$ of the alloy $\mathrm{Al}-15$ at. $\% \mathrm{Zn}$ homogenized for 21 days at $400^{\circ} \mathrm{C}$, dipped in methanol-salt-ice at $-10^{\circ} \mathrm{C}$. Deformed by $48 \%$, then aged at $160^{\circ} \mathrm{C}$ for 22 hours and finally annealed at $295^{\circ} \mathrm{C}$ for 15 minutes.

the alloy softens.

\section{REFERENCES}

[1] J. D. Verhoeven, "Discontinuous Precipitation in Binary Metallic Systems," Fundamentals of Physical Metallurgy, Vol. 1, 1942, pp. 44-56.

[2] W. Gust, "Grain Boundary Grooving as an Indicator of Grain Boundary," Phase Transformations, Vol. 1, No. 11, 1987, pp. 184-188.

[3] S. V. Sudareva, T. P. Krinitsina, Y. P. Romanov, et al., "The Effect of Chemical Doping and Hydrostatic Pressure on Tc of $\mathrm{Y}_{1-\mathrm{y}} \mathrm{Ca}_{\mathrm{y}} \mathrm{Ba}_{2} \mathrm{Cu}_{3} \mathrm{O}_{\mathrm{x}}$ Single Crystals," Zeitschrift Metalkunde, Vol. 328, No. 3, 1991, pp.127-131.

[4] N. K. Gobran, F. M. Mansy and S. S. Hansen, "Mechanism of Formation, Fine Structure, and Superconducting Properties of High-Temperature Superconductors and Superconducting Composites," Physica Status Solidi, Vol. 8, No. 3, 1983, pp. 81-86.

[5] S. M. I. Abadou, "Discontinuous Precipitation in Binary Metallic Systems," Ph.D. Thesis, Suez Canal University, Port Said, 1987.

[6] A. Guinier and I. Jacqnet, "Interprétation de la Diffusion Anormale des Rayons X par les Alliages à Durcissement Structural," Revue de Metallurgie, No. 41, 1944, pp. 121130.

[7] M. S. Sulonen, "Observations of the Effect of an Applied Stress on the Morphology of Discontinuous Precipitation in a Cu-Cd Alloy," Acta Metallurgica et Materialia, Vol. 41, No. 4, 2003, pp. 1183-1188.

[8] H. Kreye and E. Hornbogen, "Recrystallization of Supersaturated and Plastically Deformed Solid Solutions of
Nickel," Physica Status Solidi, Vol. 1, No. 1, 1970, pp. 97-108.

[9] I. Manna and S. K. Pabi, "Effect of 10 at.\% Nb Addition on Sintering and High Temperature Oxidation of $\mathrm{W}_{0.5} \mathrm{Cr}_{0.5}$ Alloy," Materials Science Forum, Vol. 710, 2012, pp. 308-313. doi:10.4028/www.scientific.net/MSF.710.308

[10] I. Manna, S. K. Pabi and W. Gust, "Enhanced Kinetics of Diffusion Coating of Aluminium on Copper by Boundary Diffusion," Journal of Materials Science, Vol. 12, No. 12, 1993, pp. 920-922.

[11] I. Manna, S. K. Pabi and W. Gust, "Diffusion Along Migrating Grain Boundaries," Journal of Materials Science, Vol. 11, No. 1, 1994, pp. 62-64.

[12] A. Guinier and G. Fournet, "Small Angle Scattering of XRays," Wiley, New York, 1955.

[13] G. D. Preston, "Microstructure of Guinier-Preston Zones in -Ag," Acta Metallurgica, Vol. 44, No. 12, 1996, pp. 4845-4852.

[14] E. P. Butler, V. Ramasvamy and P. R. Swann, "Effect of Matrix Precipitation on Cellular Growth Kinetics in an Al-28 at.\% Zn Alloy," Journal of Materials Science, Vol. 9, No. 2, 1974, pp. 240-244. doi:10.1007/BF00550947

[15] A. Pawlowski, P. Zieba and P. R. Swann, "Grain Boundary Migration in Solid State Discontinuous Reactions," Interface Science, Vol. 6, No. 1-2, 1998, pp. 113-131.

[16] I. Manna, "On the Discontinuous Precipitation Reaction and Solute Redistribution in a Cu- $15 \% \mathrm{Ni}-8 \% \mathrm{Sn}$ Alloy," Materials Characterization, Vol. 69, No. 10, 2008, pp. 1526-1530. doi:10.1016/i.matchar.2008.01.007

[17] J. R. Anantharaman, V. Ramasvany and E. P. Butler, "Structure and Properties of Spinodally Decomposed $\mathrm{Cu}-\mathrm{Ni}-\mathrm{Fe}$ Alloys," Acta Metallurgica, Vol. 18, No. 3, 1970, pp. 


\section{7-365. doi:10.1016/0001-6160(70)90150-1}

[18] A. Pawlowski and P. Zieba, "Analytical Electron Microscopy in a Discontinuous Precipitated Cu-In Alloy," Microchimica Acta, Vol. 145, No. 1-4, 2004, pp. 101-105.

[19] J. Singh, S. Lele and S. Ramganathan, "TEM Observations of Moving Interfaces during Discontinuous Precipitation Reaction in Al-22 at.\% Zn Alloy," Zeitschrift Metalkunde, No. 95, pp. 230-232.

[20] J. Singh, S. Lele and S. Ramganathan, "Discontinuous Precipitation in Co-3wt.\% Ti-2wt.\% Fe Alloy," Zeitschrift fuer Metallkunde, Vol. 72, 1981, pp. 469-475.

[21] A. Pawlowski and R. Zieba, "Defect-Induced Dynamic Pattern Formation in Metals and Alloys," Solid State Physics, Vol. 60, 2006, pp. 181-287. doi:10.1016/S0081-1947(06)80004-4

[22] G. Lutjering and S. Weissmann, "Mechanical Properties of Age-Hardened Titanium-Aluminum Alloys," Acta Metallurgica, Vol. 18, No. 7, 1970, pp. 785-795. doi:10.1016/0001-6160(70)90043-X

[23] J. Peterman and E. Hornbogen, "The Discontinuous Precipitation Reaction in Dilute Al-Li Alloys," Acta Metallurgica, Vol. 24, No. 4, 1976, pp. 323-332. doi:10.1016/0001-6160(76)90007-9

[24] K. N. Tu and D. Turbull, "Morphology of Cellular Precipitation of Tin from Lead-Tin Bicrystals," Acta Metallurgica, Vol. 15, No. 2, 1967, pp. 369-376. doi:10.1016/0001-6160(67)90214-3

[25] R. A. Fournelle and J. B. Clark, "The Cellular Reaction in
Pb-Sn Alloys," Metallurgical and Materials Transactions B, Vol. 3, No. 11, 1972, pp. 2769-2776. doi:10.1007/BF02652843

[26] J. Petermann and E. Hornbogen, "Discontinuous Coarsening of Lamellar Cellular Precipitate in an Austenitic Fe-30 wt\% Ni-6 wt\% Ti Alloy-I. Morphology," Zeitschrift Metallkunde, Vol. 4, No. 5, 1968, pp. 759-805.

[27] S. E. Bauman, J. Michael and D. B. Williams, "Grain Boundary Discontinuous Precipitation Reactions," International Metals Reviews, Vol. 26, 1981, pp. 153-183. doi:10.1179/095066081790149267

[28] A. Pawłowski and P. Zieba, "Phase Transformations: Controlled by Diffusion at Moving Boundaries," Polish Academy of Sciences, Warszawa.

[29] A. Pawlowski and R. Zieba, "Recent Progress in the Energy-Dispersive X-Ray Spectroscopy Microanalysis of the Discontinuous Precipitation and Discontinuous Dissolution Reactions," Materials Chemistry and Physics, Vol. 62, No. 3, 2000, pp. 183-213. doi:10.1016/S0254-0584(99)00179-0

[30] A. Pawlowski and W. Truszkowski, "Cellular Dissolution in the Aged Aluminium-40\% Zinc Alloy," Acta Metallurgica, Vol. 30, No. 1, 1982, pp. 37-50. doi:10.1016/0001-6160(82)90042-6

[31] M. S. Sulonen, "The Mechanism of Discontinuous Precipitation of the Metastable $\mathrm{Al}_{3} \mathrm{Zr}$ Phase from an $\mathrm{Al}-\mathrm{Zr}$ Solid Solution," Acta Metallurgica, Vol. 25, No. 9, 1977, pp. 1039-1046. doi:10.1016/0001-6160(77)90133-X 